\title{
Sensitivity of Chinese Industrial Wastewater Discharge Reduction to Direct Input Coefficients in an Input-output Context
}

\author{
TANG Zhipeng $^{1,2}$, GONG Peiping ${ }^{1,2,3}$, LIU Weidong ${ }^{1,2}$, LI Jiangsu ${ }^{4}$ \\ (1. Key Laboratory of Regional Sustainable Development Modeling, Chinese Academy of Sciences, Beijing 100101, China; 2. Institute \\ of Geographic Sciences and Natural Resources Research, Chinese Academy of Sciences, Beijing 100101, China; 3. University of Chi- \\ nese Academy of Sciences, Beijing 100049, China; 4. The Center for Yellow River Civilization and Sustainable Development of Henan \\ University, Kaifeng 475001, China)
}

\begin{abstract}
Industrial wastewater discharge in China is increasing with the country's economic development and it is worthy of concern. The discharge is primarily relevant to the direct discharge coefficient of each sector of the economy, its direct input coefficient and the final demand in input-output models. In this study, we calculated the sensitivity of the reduction in the Chinese industrial wastewater discharge using the direct input coefficients based on the theory of error-transmission in an input-output framework. Using input-output models, we calculated the direct and total industrial wastewater discharge coefficients. Analysis of 2007 input-output data of 30 sectors of the Chinese economy and of 30 provincial regions of China indicates that by lowering their direct input coefficients, the manufacturers of textiles, paper and paper products, chemical products, smelting and metal pressing, telecommunication equipment, computers and other electronic equipment will significantly reduce their amounts of industrial wastewater discharge. By lowering intra-provincial direct input coefficients to industrial sectors themselves of Jiangsu, Shandong and Zhejiang, there will be a significant reduction in industrial wastewater discharge for the country as a whole. Investment in production technology and improvement in organizational efficiency in these sectors and in these provinces can help lessen the direct input coefficients, thereby effectively achieving a reduction in industrial wastewater discharge in China via industrial restructuring.
\end{abstract}

Keywords: industrial wastewater discharge reduction; input-output; direct input coefficient; industrial restructuring

Citation: Tang Zhipeng, Gong Peiping, Liu Weidong, Li Jiangsu, 2015. Sensitivity of Chinese industrial wastewater discharge reduction to direct input coefficients in an input-output context. Chinese Geographical Science, 25(1): 85-97. doi: 10.1007/s11769-014-0666-5

\section{Introduction}

Industrial wastewater discharge has received extensive attention in China because it is one of the primary sources of water pollution. When industrial wastewater discharge causes the amounts of inorganic and organic chemicals in water to exceed certain levels, human health may be harm (Shen et al., 2010). Data (Ministry of Environmental Protection of the People's Republic of
China, 2003; 2008) have revealed that the quantity of industrial wastewater discharge in China was $2.072 \times 10^{10} \mathrm{t}$ in 2002 , accounting for $47.1 \%$ of total national wastewater discharge and $2.466 \times 10^{10} \mathrm{t}$ in 2007 , equivalent to $44.3 \%$ of the total national wastewater discharge. In 2002, the chemical oxygen demand (COD) of the national industrial discharge was $5.84 \times 10^{6} \mathrm{t}$, accounting for $42.7 \%$ of the total COD discharge, and the discharge of industrial ammonia nitrogen was $4.2 \times 10^{5} \mathrm{t}$, ac-

Received date: 2013-06-17; accepted date: 2013-10-08

Foundation item: Under the auspices of Key Program of Chinese Academy of Sciences (No. KZZD-EW-06-02), National Natural Science Foundation of China (No. 41201129), Humanities and Social Science Research Planning Fund, Ministry of Education of China (No. 13YJAZH042)

Corresponding author: TANG Zhipeng. E-mail: tangzp@igsnrr.ac.cn

(C) Science Press, Northeast Institute of Geography and Agroecology, CAS and Springer-Verlag Berlin Heidelberg 2015 
counting for $32.6 \%$ of the total ammonia nitrogen discharge. In 2007, the industrial COD discharge was $5.11 \times 10^{6} \mathrm{t}$, falling to $37.0 \%$ of the total COD discharge, and the industrial ammonia nitrogen discharge was $3.41 \times 10^{5} \mathrm{t}$, falling to $25.8 \%$ of the total ammonia nitrogen discharge. In recent years, the proportion of industrial wastewater discharge decreased relative to the increased amount of total wastewater discharge. For example, the share of Chinese industrial wastewater dropped from $46.8 \%$ in 2000 to $38.5 \%$ in 2010 , whereas its amount increased from $1.94 \times 10^{10} \mathrm{t}$ in 2000 to $2.37 \times 10^{10} \mathrm{t}$ in 2010 . For the past 20 years, China's economic growth has brought adverse effects on the environment, such as increasing amounts of industrial wastewater and solid waste emissions. Saving energy, reducing pollutant emissions and optimizing the industrial structure have become the most important and urgent tasks in achieving a green economy ( $\mathrm{Li}$ and Qi, 2011). Because of China's extremely rapid economic growth, the scale and seriousness of environmental problems are no longer in doubt (Managi and Kaneko, 2009). The top three problems listed deal with water pollution, air pollution, and hazardous waste (Ma and Ortolano, 2000). Guan and Hubacek (2007) claimed that approximately $50 \%$ of annual available freshwater resources were contaminated by wastewater discharge.

Because industrial wastewater has many characteristics, such as a wide variety, a complex set of constituents, high chemical oxygen demand and toxins, the environment may be very seriously polluted and destroyed without effective measures of pollutant reduction (Jiang et al., 2004). As the world's largest developing country, China has experienced great industrial development during the past decades, which has promoted economic growth but at the same time has resulted in elevated levels of industrial wastewater discharge. As water pollution increases, the standards of the drinking water supply and wastewater discharge become stringent (Jiang and Lloyd, 2002). A series of discharge standards for various types of wastewater, including industrial wastewater and domestic sewage, have been part of Chinese environmental protection laws since the 1980s. The Chinese government strengthened efforts to control water and air pollution in key watersheds, prevent and control air pollution and control industrial wastewater, waste gases and residues during the '11th Five-Year Plan' period (2006-2010) (Wen, 2011). Recently each provincial region in China began to reduce its industrial wastewater discharge to achieve the goal of total quantity control of water pollutants across the country in the '12th Five-Year Plan' period (2011-2015). According to the national '12th Five-Year Plan' for environmental protection, the total amounts of COD discharge will be cut by $8 \%$ by 2015 from 2010 levels, and the total emission of ammonia nitrogen would drop by $10 \%$ at the same time. In the '12th Five-Year Plan' period, China will promote the construction of key industrial wastewater treatment facilities and focus on the prevention and treatment of heavy-metal pollution (e.g., mercury, lead, chromium) in industrial wastewater through technical reform of the key industries and implement environmental pollution liability insurance for related heavy-metal enterprises in key regions. These targets have been incorporated into the mid- to long-term plans of local governments and will be achieved with the related policies and measures that Chinese local governments have promulgated.

The relationship between the economy and industrial wastewater is affected by such factors as the industrial scale, industrial structure, technical level, capital, and regime (Zhang et al., 2011). On a micro basis, the amount of industrial wastewater discharge is directly related to the enterprise's wastewater treatment technology, its level of production technology and organizational efficiency, and economic scale. On a macro basis, the total amount of industrial wastewater discharge in China is primarily related to each sector's direct discharge level, its direct intermediate input structure of raw materials and its aggregate economic activity. One sector's intermediate input structure always involves other sectors, including other regional sectors. Because close industrial associations and regional ties have been maintained during the process of globalization (Liu et al., 2012), a small change in one sector's input or one intra-regional industrial input may cause large changes in other industries or regions. The changes in industrial structures in each sector or in each provincial region will affect the entire national economy of China. To maximize the reduction of industrial wastewater discharge, it is essential to analyze the sensitivity of the reduction in Chinese industrial wastewater discharge for each industrial sector and each region in the national economic system. Previous researches have focused on two fields of wastewater discharge reduction: the pre- 
diction of industrial wastewater discharge in China (Yu et al., 2003; Yu et al., 2009; Li and Pan, 2011) or the assessment of industrial wastewater discharge in Chinese cities (Zhang, 2011) and the analysis of the factors influencing industrial wastewater discharge (Xie et al., 2004b; Li et al., 2009; Zhou, 2010; Liu et al., 2011; Tang et al., 2011). These research results focus on industrial wastewater discharge from the perspective of single industries, while others focus on water pollutant discharge from the perspective of industrial associations (Okadera et al., 2006; Tang et al., 2008 Tang et al., 2009). During recent years, China's economic development has been transforming from 'extensive' to 'intensive' to protect the environment. Therefore, the restructuring of industry is an important factor in reducing pollution.

Pollution is a by-product of regular economic activities. For example, the discharge of polluted water into streams and lakes is linked directly to the level of output of the steel, paper, textile and other water-using industries (Leontief, 1970). Input-output analysis may describe and explain the level of each sector in a given national economy in terms of its relationships to corresponding levels of activity in all of the other sectors, and even the spatial patterns of the economy may be described and explained by a complex multi-regional input-output approach (Leontief, 1970). The input-output model proposed by Leontief is an appropriate method for studying industrial associations and regional ties. In input-output theory, the coefficients of the Leontief inverse matrix represent the intermediate input structure. They imply industrial associations and regional ties, whereas direct input coefficients directly reflect the industrial input structure with regard to various sectors and regions (Zhong et al., 1993). The input-output model has been widely used in the environmental protection field (Kneese et al., 1970; Johnson and Bennett, 1981; Rhee and Miranowski, 1984; Miller and Blair, 1985; Chen et al., 2011). In addition, this model may be used to calculate the direct, indirect and total discharge of each sector's or regional industrial wastewater. According to the environmental input-output model, changes in pollution primarily arise from two aspects. One, the changes originate from various coefficients, including the direct emission coefficients and direct input coefficients. Two, the changes are also a result of the final demand, including consumptions, investments and exports. Obviously the first approach focuses on the changes in the productive structure of the system assuming that the final demand is fixed, whereas the second approach results from the consequences of changes in the flow variables of final demand for a given technological structure (Tarancón and Río, 2012). In fact, the two aspects influence the changes in environmental pollution together. The first approach is often referred to as structural ex-ante analysis. It may be used to analyze each sector's or region's sensitivity to small changes in the input coefficients of the industrial structure.

Because restructuring is a primary goal of the '12th Five-Year Plan' period, this study used an input-output model to calculate the sensitivity of the total industrial wastewater discharge variation across the entire country in 2007. It means that we could get the information of the policy-making decisions in industrial structuring when the key input coefficient in each sector was less than $1 \%$. We also calculated the sensitivity of variations in the total amount of industrial wastewater discharge across the entire country in 2007, when the industrial input coefficient in each provincial region was less than $1 \%$. We thus identified certain sectors and provincial regions that are important to reducing industrial wastewater discharge by examining where these input coefficients result in highly sensitive discharge reductions. The identification of these important sectors and provincial regions may provide guidance for regional industrial policy-making regarding wastewater discharge reduction and may help in the development of an environment-friendly society.

\section{Materials and Methods}

\subsection{Data sources}

The data in this study were primarily obtained from two input-output tables, which are the latest publicly available input-output data. One table is the 2007 Chinese input-output table issued by the National Statistic Bureau of China (2009). This table includes data on forty-two industrial sectors. As manufacturing is typically highly industrialized, we retained the majority of the manufacturing data. Because of its high industrial wastewater discharge, the sector of manufacturing of paper and paper products was separated from the sector of paper products and printing and record medium reproduction based on Chinese 135 sector's input-output 
table in year 2007. Then we merged some service sectors and reduced the number of sectors from 135 to 30 (Table 1).

The first 21 sectors are industrial sectors and they discharge industrial wastewater directly, whereas the latter 9 sectors produce no direct industrial wastewater discharge. The other table is the Chinese 30 provincial multi-regional input-output table for the year 2007, compiled by the researchers of Institute of Geographic Sciences and Natural Resources Research of Chinese Academy of Sciences and the National Statistic Bureau of China (Liu et al., 2012).

At present, only the Chinese 30 provincial multiregional input-output table for 2007 is publicly available. Tibet, Taiwan, Hong Kong and Macau of China are excluded for lack of input-output data. There are seldom large changes in the direct input coefficients in the input-output table from one compilation to the next, which indicates structural stability in the short term. We therefore used the input-output data for 2007 as cross-section data for a structural ex-ante analysis. This manner of handling the data had no impact on our analysis. Based on this multi-regional input-output table, we divided all of the sectors of each province into two types: the industrial sector and non-industrial sector. By dividing each sector's industrial wastewater discharge amount by the industrial output, we obtained each sector's direct discharge coefficient of industrial wastewater. The results are environmental data regarding the amount of industrial wastewater discharge in China, which are from Statistical Yearbook of China 1991-2007(National Bureau of Statistic of China, 1992-2008).

\subsection{Methodology}

An input-output model is a mathematic-economic model of the quantitative relationships of a product's production and consumption between various industries (Chen et al., 1985). As such an input-output model can be used to characterize the mutual dependence of all departments in the national economic system by quantitative analysis, it is a quantitative model combining economics and management science with mathematics. Such a model may also integrate a part of the national economy into the whole and be used to analyze those economic relations that are difficult to observe directly. Thus, an input-output model is a basic quantitative analytical tool to enhance macroeconomic controls and make scientific decisions (Shi et al., 2012). In the input-output table, the direct input coefficients represent the relationship between production and consumption among various industries and express the industrial input structure. The direct input coefficients reflect the level of production

Table 1 Classification of economic sectors in 2007

\begin{tabular}{|c|c|c|c|}
\hline $\begin{array}{c}\text { Sector } \\
\text { number } i\end{array}$ & Description & $\begin{array}{c}\text { Sector } \\
\text { number } i\end{array}$ & Description \\
\hline 1 & Mining and washing of coal & 16 & Metal products \\
\hline 2 & $\begin{array}{l}\text { Mining and processing of metal ores and nonmetal } \\
\text { ores }\end{array}$ & 17 & Common and special equipment \\
\hline 3 & Manufacture of foods, beverages and tobacco & 18 & Transportation equipment \\
\hline 4 & Manufacture of textiles & 19 & Electric equipment and machinery \\
\hline 5 & Manufacture of paper and paper products & 20 & $\begin{array}{l}\text { Telecommunication equipment, computer and other electronic } \\
\text { equipment }\end{array}$ \\
\hline 6 & $\begin{array}{l}\text { Petroleum processing, coking and nuclear fuel proc- } \\
\text { essing }\end{array}$ & 21 & $\begin{array}{l}\text { Instruments, meters, cultural and office machinery and other } \\
\text { manufacturing products }\end{array}$ \\
\hline 7 & Chemical products & 22 & Agriculture \\
\hline 8 & Smelting and pressing of metals & 23 & Construction \\
\hline 9 & $\begin{array}{l}\text { Production and supply of electric power, steam and hot } \\
\text { water }\end{array}$ & 24 & Transportation and warehousing \\
\hline 10 & Extraction of petroleum and natural gas & 25 & Post \\
\hline 11 & $\begin{array}{l}\text { Manufacture of textile wearing apparel, leather, furs, } \\
\text { and related products }\end{array}$ & 26 & Wholesale and retail trade \\
\hline 12 & $\begin{array}{l}\text { Processing of timber, manufacture of wood and furni- } \\
\text { ture }\end{array}$ & 27 & Accommodation, eating and drinking places \\
\hline 13 & Printing and record medium reproduction & 28 & Finance and insurance \\
\hline 14 & Manufacture of cultural and educational products & 29 & Real estate \\
\hline 15 & Manufacture of non-metallic construction products & 30 & Other social services \\
\hline
\end{tabular}


technology and the organizational efficiency and are described as the technical coefficients (Chen et al., 1985). The input-output model of a single region is expressed by the equations (1) and (2):

$X=(I-A)^{-1} Y=\left(I+A+A^{2}+A^{3}+\ldots\right) Y=B Y(1)$

$B=(I-A)^{-1}=I+A+A^{2}+A^{3}+\ldots$

where supposing there are $n$ sectors in the national economy, $X=\left(x_{1}, x_{2}, \ldots, x_{n}\right)^{\mathrm{T}}$ is the column vector of the total output, here the superscript $T$ means vector transpose; $A=\left[a_{i j}\right](i, j=1,2, \ldots, n)$ is the matrix of the direct input coefficients, $a_{i j}$ is the quantity of sector $i$ absorbed by an additional unit of total output of sector $j$; $I$ is identity matrix; $B=\left[b_{i j}\right]=(I-A)^{-1}(i, j=1,2, \ldots, n)$ is the matrix of the Leontief inverse coefficients, $b_{i j}$ is total amounts of sector $i$ in the national economy needed by an additional unit of final demand of sector $j$; and $Y$ $=\left(y_{1}, y_{2}, \ldots, y_{n}\right)^{\mathrm{T}}$ is the column vector of the final demand. Here $a_{i j}$ and $b_{i j}$ are the elements of the matrices $A$ and $B$ respectively, and the subscripts $i$ and $j$ are the corresponding positions of $a_{i j}$ and $b_{i j}$ in the input-output table, i.e., a complete set of the input coefficients of all sectors of a given economy arranged in the form of a rectangular table called the structural matrix of this economy (Leontief, 1986).

When applying to industrial wastewater discharge, the row vector of the direct industrial wastewater discharge coefficients are introduced into above equations. Equations (1) and (2) may be expressed as equations (3) and (4), respectively.

$E=e X=e(I-A)^{-1} Y=f Y$

$f=e(I-A)^{-1}$

where $e=\left(e_{1}, e_{2}, \ldots, e_{n}\right)$ is the row vector of the direct industrial wastewater discharge coefficients; $f=\left(f_{1}\right.$, $f_{2}, \ldots, f_{n}$ ) is the row vector of the total industrial wastewater discharge coefficients; and $E$ is the total amount of industrial wastewater discharge. The factors affecting industrial wastewater discharge primarily include the economic scale, economic structure and level of development of the treatment technology (Xie et al., 2004a).

Based on Equation (3), the structural decomposition analysis in the input-output technique may divide the total industrial wastewater discharge into three factors: The first factor is the row vector of the direct discharge coefficient per unit of total output $e$. The second factor is the Leontief inverse matrix $(I-A)^{-1}$, which consists of direct input coefficients $a_{i j}$ and reflects the intermediate input and demand structure among the interdependent sectors. The last factor is the final demand column vector $Y$, the sum of its various items equals GDP, which provides an indication of economic growth. The first factor $e$ is related to the wastewater treatment technology. Conventional industrial wastewater treatment techniques consist primarily of four methods at present: the physical method, chemical method, physicochemical method and biological method ( $\mathrm{Lu}$ and Liu, 2006). A high state of development of the treatment technology is important for reducing industrial wastewater discharge. For example, the total industrial wastewater discharge increased little along with the total industrial output because of the progress in wastewater treatment. The last factor $Y$ represents the scale of economic growth and is positively associated with the total discharge of industrial wastewater. However, we do not discuss here the influence of the first factor $e$ and the last factor $Y$ on industrial wastewater discharge. We primarily studied the impact of the second factor $(I-A)^{-1}$. Because the intermediate input and demand structure are very important in pollutant emission reductions (Fan, 2008), based on Equation (2), the direct input coefficient $a_{i j}$ has an immediate function as the basic element of the intermediate input and demand structure. From equations (3) and (4), we determined that when any direct input coefficient $a_{i j}$ changes by $1 \%$, each sector's total industrial wastewater discharge coefficient and the total industrial wastewater discharge amount in the entire economy will vary. We can apply the direct input coefficients that cause the maximum variation in the industrial wastewater discharge in each sector and province across the country. Studies of important coefficient methods in input-output theory (Sonis and Hewings, 1992; Xu, 2003; Tang and Wang, 2007) indicate that slight changes in the direct input coefficients will result in variations in the total discharge coefficients because of changes in the Leontief inverse coefficients. An important coefficient method (Xu and Madden, 1991) based on the theory of error-transmission (Sherman and Morrison, 1950; Tarancón et al., 2010) is expressed by the Equation (5).

$$
\Delta b_{i j}=\frac{b_{i k} b_{l j} \Delta a_{k l}}{1-b_{l k} \Delta a_{k l}}
$$

Equation (5) shows how the Leontief inverse coeffi- 
cient $b_{i j}$ will vary when the direct input coefficient $a_{k l}$ has changed by an amount $\Delta . \Delta a_{k l}$ and $\Delta b_{i j}$ mean the variations of the coefficients $a_{k l}$ and $b_{i j}$ respectively, here the subscripts in Equation (5) are the corresponding positions of these coefficients in the input-output table, the specific subscripts $i$ and $j$ mean the corresponding sectors. Eight equations based on the theory of error-transmission (Xu and Madden, 1991), including those expressing the absolute and relative variations in the Leontief inverse coefficient $b_{i j}$, have been derived from Equation (5). We adopt two of these equations to calculate the relative variation in the total output $X_{i}$ and the Leontief inverse coefficient $b_{i j}$ based on equations (1) and (2). These relative variations are expressed as equations (6) and (7), respectively.

$$
\begin{aligned}
& R_{X}=\frac{\Delta X_{i}}{X_{i}}=\left|\frac{b_{i k} X_{l} \Delta a_{k l}}{X_{i}\left(1-b_{l k} \Delta a_{k l}\right)}\right| \\
& R_{b}=\frac{\Delta b_{i j}}{b_{i j}}=\left|\frac{b_{i k} b_{l j} \Delta a_{k l}}{b_{i j}\left(1-b_{l k} \Delta a_{k l}\right)}\right|
\end{aligned}
$$

where $R_{X}$ and $R_{b}$ are values of the relative variation about $X_{i}$ and $b_{i j}$, respectively. When the direct input coefficient $a_{k l}$ has relatively changed by $\Delta$, the subscripts $i, j$, $k$ and $l$ in equations (6) and (7) indicate the corresponding sectors in the input-output table. We could get the relative variations about the total output $X_{i}$ and the Leontief inverse coefficient $b_{i j}$ by equations (6) and (7).

When Equation (7) is modified and expanded based on Equation (5), it can be expressed as Equation (8). Equation (8), which is based on Equation (3), specifies the relative variation in the total industrial wastewater discharge coefficient $f_{i}$ of sector $i$ and is expressed as follows:

$R_{f}=\frac{\Delta f_{i}}{f_{i}}=\left|\frac{f_{k} b_{l i} \Delta a_{k l}}{f_{i}\left(1-b_{l k} \Delta a_{k l}\right)}\right|$

where $f_{i}$ is the total industrial wastewater discharge coefficient of sector $i$, and similarly $R_{f}$ is the relative variation around $f_{i}$. When $a_{k l}$ has relatively changed by $\Delta$, the subscripts $i, k$ and $l$ in equations (6) and (7) indicate the corresponding sectors. Therefore, we are able to select the specific $a_{k l}$ that causes the maximum relative variation of each $f_{i}$. In addition, we may obtain the variation of industrial wastewater discharge as follows:

$\Delta E=\Delta f Y$
In Equation (9), $\Delta E$ is the absolute variation of the total industrial wastewater discharge, and $\Delta f$ is the variation of the row vector of the total industrial wastewater discharge coefficients. For $i$ from 1 to $n$, we can obtain $n$ for various values of $f_{i}$ according to $a_{k l}$, and obtain the absolute variation of the total industrial wastewater discharge from Equation (9). In this paper, $n$ is 30 , according to Table 1 . We set that $\Delta$ equals $1 \%$ and selected the specific $a_{k l}$ that caused the maximum relative variation of each $f_{i}$ based on Equation (8). Next, we calculated $\Delta E$ according to each $a_{k l}$ decrease of $1 \%$ on the condition that the exogenous variable $Y=\left(y_{1}, y_{2}, \ldots\right.$, $\left.y_{n}\right)^{T}$ is held constant by Equation (9). Finally we selected a maximum $a_{k l}$ by comparing the various derived results and identified the sectors most important for the reduction of industrial wastewater in China. All of above formulas are applied to single-region such as the whole country. When spatially applied to industrial wastewater discharge, suppose there are $m$ regions in China and $n$ sectors in each region, similarly, equations (10) and (11) are expressed, respectively, as follows:

$$
R_{f}^{z}=\frac{\Delta f_{i}^{z}}{f_{i}^{z}}=\left|\frac{f_{k}^{q} b_{l i}^{p z} \Delta a_{k l}^{q p}}{f_{i}^{z}\left(1-b_{l k}^{p q} \Delta a_{k l}^{q p}\right)}\right|
$$

$\Delta E^{z}=\Delta f^{z} Y$

As the coefficients in equations (8) and (9) are expanded from single-region to multi-region, we mark them in equations (10) and (11) by different superscripts to distinguish them. For example, the superscripts $z, p$ and $q$ in relevant variables denote the corresponding region, and the subscripts $i, k$ and $l$ denote the corresponding sectors.

When the direct input coefficient $a_{k l}^{q p}$ between regions $q$ and $p$ has relatively changed by $\Delta$, using Equation (10) we could get the relative variation of total industrial wastewater discharge coefficient in region $z$, namely $R_{f}^{z}$. Of course, we select the specific $a_{k l}^{q p}$ that causes the maximum relative variation of each $f_{i}^{z}$ by Equation (10). Then by Equation (11), we obtain the maximum variation of industrial wastewater discharge $\Delta E^{z}$ on the condition that the exogenous variable $Y=\left(y_{1}^{1} \cdots y_{n}^{1} ; \cdots ; y_{1}^{z} \cdots y_{n}^{z} ; \cdots ; y_{1}^{m} \cdots y_{n}^{m}\right)^{\mathrm{T}}$ is held constant, here $Y$ is the column vector of final demand about $m$ regions and $n$ sectors in each region. In Equation (11), 
using the above formulas we may calculate the sensitivity of Chinese industrial wastewater discharge reduction to the direct input coefficients. In other words, we need to select the key direct input coefficients of 30 sectors and of 30 provinces of China which are highly sensitive to discharge reduction. And the backward linkage coefficient $u_{j}$ of sector $j$ and the forward linkage coefficient $v_{i}$ of sector $i$ can be expressed, respectively, as follows:

$u_{j}=\frac{\frac{1}{n} \sum_{i=1}^{n} b_{i j}}{\frac{1}{n^{2}} \sum_{i=1}^{n} \sum_{j=1}^{n} b_{i j}} \quad v_{i}=\frac{\frac{1}{n} \sum_{j=1}^{n} b_{i j}}{\frac{1}{n^{2}} \sum_{i=1}^{n} \sum_{j=1}^{n} b_{i j}}$

If both $u_{j}$ and $v_{i}$ more than 1 , further more, $j$ equals $i$, sector $j$ or $i$ has strong powers of dispersion both for backward linkage and forward linkage (Sonis et al., 2000).

\section{Results}

The gross amount of industrial wastewater discharge had a clear decrease from 1991 to 2000 but a gradual increase from 2000 to 2007 in China. There was more gross discharge in 2007 than in 1991. Though the amounts fluctuated in a narrow range, they nevertheless exhibit an early general downward trend and a later gradual upward trend. From 1991 to 2007, the total industrial output value in China increased significantly, while the gross amount of industrial wastewater discharge did not during the same period. These trends imply that the factor of industrial scale is not critical for industrial wastewater discharge reduction (Fig. 1).

Based on Table 1, we obtained the amount of industrial wastewater discharged per unit output in each of the 21 industrial sectors in 2007 (Fig. 2). The other 9 sectors did not discharge industrial wastewater directly and their direct industrial wastewater discharges are zero. Figure 2 shows that sector 5 experienced far more industrial wastewater discharge per unit output than other sectors. Sector 5 consists of the manufacture of paper and paper products, as shown in Table 1.

The manufacture of paper and paper products creates substantial discharges of industrial wastewater, and this sector creates the highest discharges of industrial wastewater in the national economy. Using the 2007 Chinese input-output table and environmental data, we calcu-

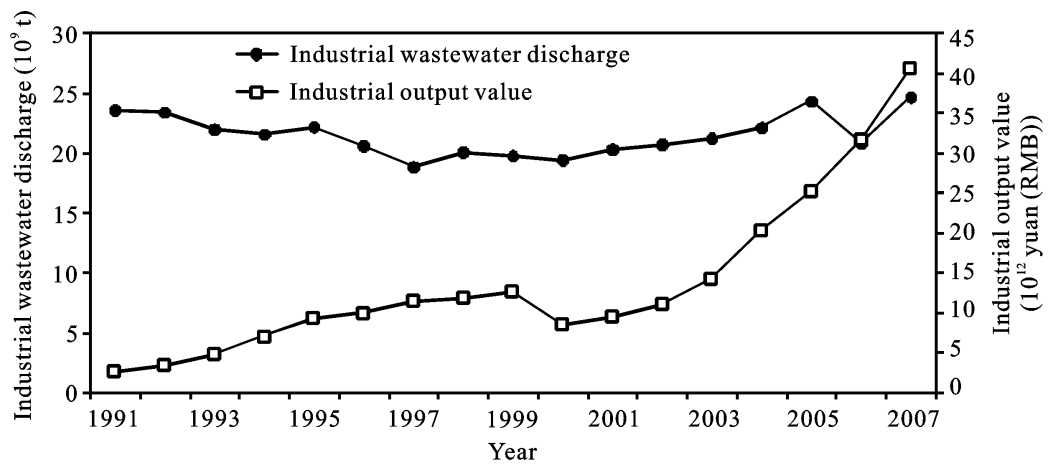

Fig. 1 Gross amount of industrial wastewater discharge and total industrial output value in China from 1991 to 2007

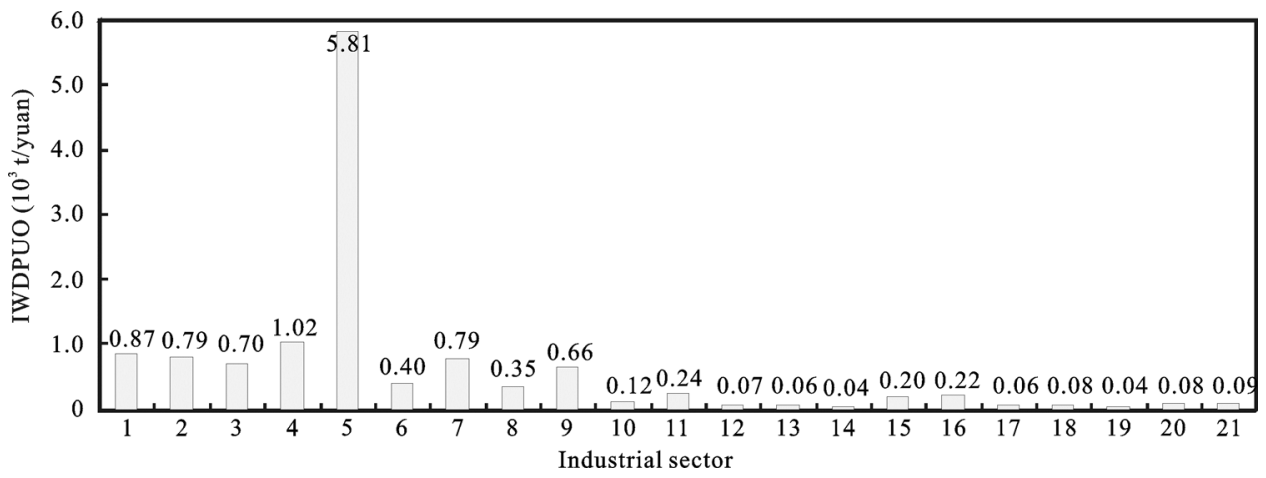

Fig. 2 Chinese industrial wastewater discharge per unit output (IWDPUO) of 21 industrial sectors in 2007 
lated the relevant input-output coefficients of 30 sectors, as outlined in Table 1. We obtained the row vector of the direct industrial wastewater discharge $e=(0.87,0.79$, $0.70, \ldots, 0)_{1 \times 30}$. Equation (4) yields the row vector of the total industrial wastewater discharge coefficient $f=$ $(1.49,1.61,1.49, \ldots, 0.75)_{1 \times 30}$.

The industrial wastewater discharges are mostly concentrated in the eastern coastal China because of their high relative levels of industrialization. For example, the amount of industrial wastewater discharge in Jiangsu Province was $2.69 \times 10^{9} \mathrm{t}$, which was far higher than that of other provinces. Next was Guangdong Province, where $2.46 \times 10^{9} \mathrm{t}$ was discharged. In 2007 , more than $1.6 \times 10^{9} \mathrm{t}$ was discharged in such provinces as Jiangsu, Zhejiang, Shandong, Guangdong and Guangxi (Fig. 3). Hainan had the least industrial wastewater discharge, i.e., $5.96 \times 10^{7} \mathrm{t}$; and the second least amount, $7.32 \times 10^{7} \mathrm{t}$, was observed in Qinghai.

Using equations (8) and (9), the calculated results of the sensitivity of Chinese industrial wastewater discharge reductions in 2007 are presented in Table 2. Here $a_{k, l}$ is the same meaning as $a_{k l}$ in order to express the specific subscripts of $a_{k l}$ clearly. From Table 2, we easily know when the direct input coefficient $a_{7,7}$ was decreased by $1 \%$ in 2007 , the total industrial wastewater discharge displayed the greatest reduction $\left(5.58 \times 10^{7} \mathrm{t}\right)$ in China (Table 2). By calculation, we found that sector 7 displays strong powers of dispersion both for the backward linkage coefficient $u_{7}=1.67$ and the forward linkage coefficient $v_{7}=2.78$, both of which are more than 1 . In other words, the chemical products sector displays a strong industrial linkage effect. In addition, the direct input coefficient $a_{7,7}$ is much larger than the other direct input coefficient of sector 7 , and thus this direct input coefficient is the most important coefficient for industrial wastewater reduction. The most important direct input coefficient in reducing industrial wastewater discharge is $a_{7,7}$, followed by $a_{8,8}$. When $a_{8,8}$ is decreased by $1 \%$, the industrial wastewater discharge amount was reduced by $2.91 \times 10^{7} \mathrm{t}$. A reduction of $1 \%$ in the other twenty-eight input coefficients resulted in a similar pattern of reduction in industrial wastewater discharge. We classified these direct input coefficients into three types (Notes under Table 2) based on the level

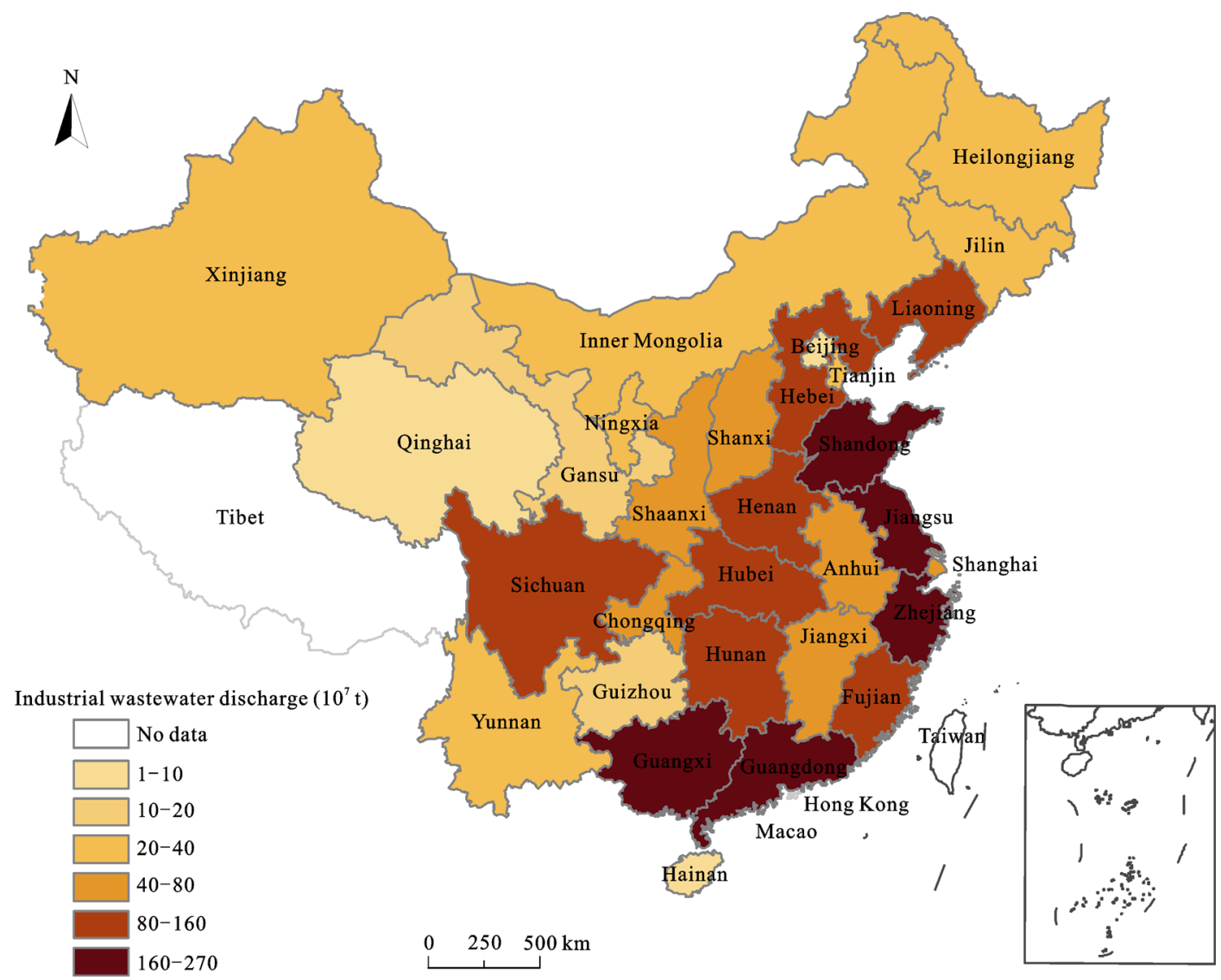

Fig. 3 Chinese provincial industrial wastewater discharge amounts in 2007 
of industrial wastewater discharge reduction in 2007. This classification helped us to identify certain key discharge reduction sectors related to these direct input coefficients. The data in Table 2 show that certain direct input coefficients in the industrial structure were closely related to industrial wastewater discharge reduction in 2007. From Table 2, sectors with lower direct input, namely lower direct input coefficients, such as sectors 7 (chemical products), 8 (smelting and pressing of metals), 4 (manufacture of textiles), 5 (manufacture of paper and paper products) and 20 (telecommunication equipment, computer and other electronic equipment), merit attention for potential reductions in the amounts of industrial wastewater discharge. Thus the direct input coefficients $a_{4,4}, a_{5,5}, a_{7,7}, a_{8,8}$ and $a_{20,20}$ are important to large reductions in industrial wastewater discharge for the whole country.

Besides sector 7, the sectors in general display strong powers of dispersion for the backward linkage coefficients $u_{j}$ and the forward linkage coefficients $v_{i}$. For example, sectors 4,8 and 20 display values of $u_{4}=1.16$ and $v_{4}=1.01, u_{8}=1.18$ and $v_{8}=2.37, u_{20}=1.35$ and $v_{20}$ $=1.21$, respectively. Sector 5 is associated with the highest amount of industrial wastewater discharge per unit output of all of the sectors. In addition, all of these direct input coefficients display the same characteristics, i.e., are much larger than the other direct input coefficients in this sector. All of these results are for the various sectors across the entire country. The sensitivities of industrial wastewater discharge reductions among the Chinese provinces warranted additional analysis and discussion. We calculated the sensitivities of the Chinese industrial wastewater discharge reductions when each provincial industrial sector's direct input coefficient was decreased by $1 \%$ in 2007 using equations (10) and (11). We found that the industrial wastewater discharge reduction in four the eastern coastal provincial regions changed greatly (Fig. 4).

When the industrial sector's direct input coefficient of Jiangsu Province decreased by $1 \%$ in 2007 , the industrial wastewater discharge was reduced by $2.65 \times 10^{7} \mathrm{t}$ for the entire country, which was far higher than that of other provinces. Next was that of Shandong Province, which resulted in a reduction of $2.27 \times 10^{7} \mathrm{t}$ for the entire country. Guangdong Province was in the fourth place, with $1.92 \times 10^{7} \mathrm{t}$ of reduction, behind Zhejiang Province's reduction of $1.97 \times 10^{7} \mathrm{t}$. In contrast, Hainan Province resulted in the least industrial wastewater discharge reduction, $1.92 \times 10^{5} \mathrm{t}$, and Qinghai Province was the second least, with $5.12 \times 10^{5}$ t. Beijing was in fourth place, with $9.32 \times 10^{5}$ t, behind Gansu Province, which resulted in a reduction of $8.99 \times 10^{5} \mathrm{t}$.

Table 2 Sensitivity of Chinese industrial wastewater discharge reduction to relative variation of $1 \%$ in direct input coefficient $\left(a_{k, l}\right)$ in 2007

\begin{tabular}{|c|c|c|c|c|c|c|c|}
\hline $\begin{array}{c}\text { Sector } \\
\text { number } i\end{array}$ & Specific $a_{k, l}$ & $\begin{array}{l}\text { Relative variation } \\
\text { in } f_{i}(\%)\end{array}$ & $\begin{array}{l}\text { Absolute variation } \\
\text { in } \Delta E(\mathrm{t})\end{array}$ & $\begin{array}{c}\text { Sector } \\
\text { number } i\end{array}$ & Specific $a_{k, l}$ & $\begin{array}{l}\text { The relative variation } \\
\text { in } f_{i}(\%)\end{array}$ & $\begin{array}{l}\text { Absolute variation } \\
\text { in } \Delta E(\mathrm{t})\end{array}$ \\
\hline 1 & $a_{1,1}{ }^{* *}$ & 0.12 & 1447914 & 16 & $a_{8,16}{ }^{* *}$ & 0.45 & 8957152 \\
\hline 2 & $a_{9,2}{ }^{* *}$ & 0.13 & 1840643 & 17 & $a_{8,17}{ }^{* * *}$ & 0.41 & 11917384 \\
\hline 3 & $a_{3,3}{ }^{* * *}$ & 0.25 & 11860468 & 18 & $a_{18,18^{* * *}}$ & 0.50 & 10971281 \\
\hline 4 & $a_{4,4}{ }^{* * *}$ & 0.63 & 24558619 & 19 & $a_{8,19}{ }^{* * *}$ & 0.41 & 10856789 \\
\hline 5 & $a_{5,5}{ }^{* * *}$ & 0.41 & 21407997 & 20 & $a_{20,20}{ }^{* * *}$ & 1.11 & 23135892 \\
\hline 6 & $a_{10,6}{ }^{* *}$ & 0.37 & 7173038 & 21 & $a_{7,21}{ }^{* *}$ & 0.21 & 2567650 \\
\hline 7 & $a_{7,7}{ }^{* * *}$ & 0.76 & 55882876 & 22 & $a_{7,22}{ }^{* *}$ & 0.45 & 8132491 \\
\hline 8 & $a_{8,8}{ }^{* * *}$ & 0.55 & 29078045 & 23 & $a_{15,23}{ }^{* * *}$ & 0.30 & 17443325 \\
\hline 9 & $a_{9,9}{ }^{* * *}$ & 0.56 & 18717659 & 24 & $a_{6,24}{ }^{* *}$ & 0.43 & 6139545 \\
\hline 10 & $a_{9,10}{ }^{* *}$ & 0.21 & 1110509 & 25 & $a_{13,25}{ }^{*}$ & 0.20 & 129456 \\
\hline 11 & $a_{4,11}{ }^{* * *}$ & 0.57 & 15149406 & 26 & $a_{30,26}{ }^{* *}$ & 0.21 & 2169857 \\
\hline 12 & $a_{12,12}{ }^{* *}$ & 0.41 & 3205345 & 27 & $a_{3,27}{ }^{* *}$ & 0.63 & 6575883 \\
\hline 13 & $a_{5,13}{ }^{* * *}$ & 0.89 & 12517309 & 28 & $a_{5,28}{ }^{* *}$ & 0.30 & 1741938 \\
\hline 14 & $a_{5,14^{* *}}$ & 0.32 & 1538447 & 29 & $a_{30,29}{ }^{*}$ & 0.17 & 413948 \\
\hline 15 & $a_{15,15^{* *}}$ & 0.20 & 4939729 & 30 & $a_{7,30}{ }^{* * *}$ & 0.24 & 13180920 \\
\hline
\end{tabular}

Notes: For each coefficient's sensitivity, the superscript $* * *$ indicates that the discharge amount is more than $1 \times 10^{7} \mathrm{t}$, ** indicates that the discharge amount is $1 \times 10^{6} \mathrm{t}-1 \times 10^{7} \mathrm{t}$, and $*$ indicates that the discharge amount is less than $1 \times 10^{6} \mathrm{t}$ 


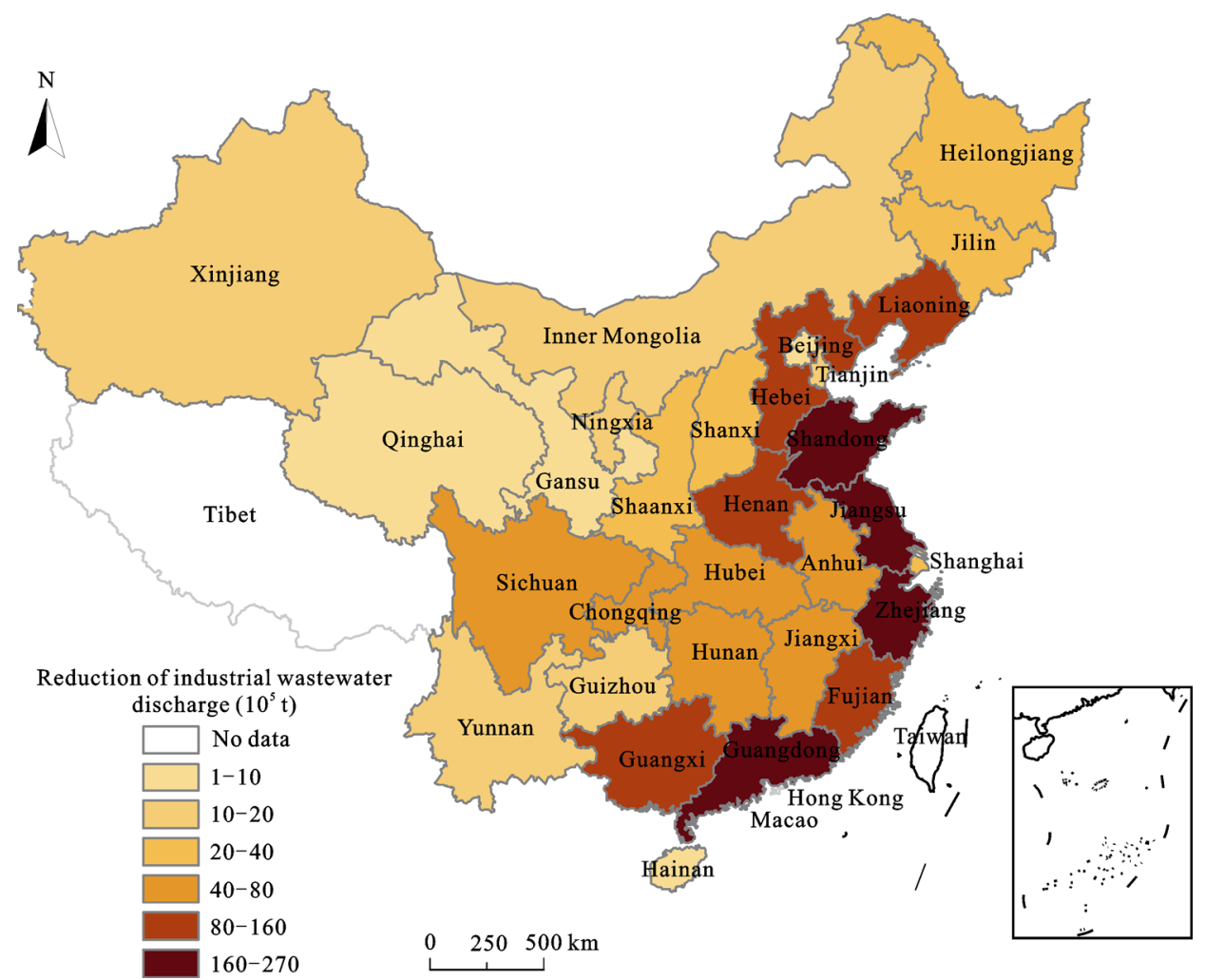

Fig. 4 Reduction in Chinese industrial wastewater discharge on condition that each provincial direct input coefficient for industrial sector input to industrial sector decreased by $1 \%$ in 2007

Each change in the direct input coefficients precipitated a different variation in the industrial wastewater discharge in the input-output context because of industrial associations and regional ties. Although similarities and differences exist between important coefficient and elasticity coefficient analyses in the input-output analysis (Schnabl, 2003), the direct input coefficient in an input-output model plays a key role. Given the urbanization and expected future economic growth in China, the final demand for goods and services is unlikely to decrease, and a clear change in the direct discharge coefficients will rely on the development of treatment technologies, which takes a great deal of time. Therefore, we have not discussed the two factors $Y$ and $e$ which are related to industrial wastewater discharge reduction. The factor $\left(\begin{array}{ll}I & A\end{array}\right)^{1}$ and the change in its basic element $a_{i j}$ represents an effective focal point for reducing industrial wastewater discharge. A change in $a_{i j}$ means the structural adjustment of the corresponding sector's intermediate input. This restructuring has been underway since the '11th Five-Year Plan' and has become a major theme of the '12th Five-Year Plan'. Decreasing the values of certain key direct input coefficients may help to reduce industrial wastewater discharge. This possibility means that it is necessary to increase the service sector's input share of relevant key sectors and key regions in the '12th Five-Year Plan'. A number of issues warrant future research. This study evaluated the sensitivity of industrial wastewater discharge reduction to the direct input coefficients based on a theory of error transmission within an input-output analysis framework. Based on our analysis, we believe that a total discharge reduction is more comprehensive than a single sector's discharge reduction. It is also clear from this study that lessening certain coefficients in key sectors and key regions will efficiently reduce industrial wastewater discharge across the entire country.

\section{Discussion}

The purpose of this paper was to provide an overview of sensitivity analyses within an input-output framework applied to industrial wastewater discharges. This sensitivity analysis of direct input coefficients allowed us to assess the impact on industrial wastewater discharges of the various coefficients that make up the productive 
structure of the economic system. We studied the industrial wastewater discharge reduction based on the implicit assumptions that the final demand and the direct discharge coefficients are both fixed. The gross final demand equals GDP in the input-output tables. Thus one of the implicit assumptions is that fixed final demand means flat economic growth. Another assumption is that fixed direct discharge coefficients mean an unchanged set of wastewater treatment technologies. In addition, this method has certain limitations because of certain assumptions deviating from actual economic conditions, such as the linearity of productive relationships, a lack of endogenous final demands and inattention to the impact of prices (Tarancón and Río, 2012). Clearly these limitations are not realistic because economic fluctuation is not always linear, the endogenous consumptions would form extended Leontief inverse coefficients and the changes in prices also influence restructuring.

However, this sensitivity analysis may help us to measure industrial wastewater discharge reduction caused by the changes in the intermediate input of industrial restructuring. This type of analysis may be applied to not only industrial wastewater discharge reduction but also other pollution emissions. Therefore, an interesting question is how to lessen these key coefficients of the sectors, specifically whether this process should be accomplished by improving the production technical level or the efficiency of management and the associated costs of making these changes. This is another problem that merits study. Because the direct input coefficients in the input-output table directly reflect the industrial associations and regional ties of the national economy, the recent industrial reconstruction will obviously change the direct input coefficients of each sector and each region in the entire national economy. Naturally, our results provide support for further academic study and practical and detailed guidance for government decisions on industrial reconstruction.

\section{Conclusions}

As previously mentioned, this paper is a structural ex-ante analysis based on the assumption of fixed final demand and technological development related to the direct discharge coefficient. Therefore, these results may help develop the restructuring policies with regard to industrial wastewater reduction. The input-output method provides a pollution reduction sensitivity assessment that takes into account industrial associations and regional ties across the entire economic system. From the above results, we may find the input coefficient that has either a larger value or a stronger power of dispersion for the backward linkage and forward linkage than other input coefficients and thus has a greater effect on industrial wastewater discharge. The additional conclusions are as follows:

(1) We calculated the sensitivity of the reduction of Chinese industrial wastewater discharge to a $1 \%$ relative variation in certain key direct input coefficients in the 2007 input-output table. The key direct input coefficients $a_{4,4}, a_{5,5}, a_{7,7}, a_{8,8}$ and $a_{20,20}$ were important to large reductions in industrial wastewater discharge. Lower intermediate input ratios for the fourth (manufacture of textiles), fifth (manufacture of paper and paper products), seventh (chemical products), eighth (smelting and pressing of metals) and twentieth (telecommunication equipment, computer and other electronic equipment) industrial sectors will help to significantly reduce industrial wastewater discharge. The majority of these sectors are in the high discharge category for industrial wastewater.

(2) Spatially, high discharge of Chinese industrial wastewater is mostly concentrated in the east coastal regions, such as Jiangsu, Guangdong, Zhejiang and Shandong provinces. If the provincial industrial sector direct input coefficients had been decreased by $1 \%$ in 2007, then such a decrease in Jiangsu Province would have resulted in the largest discharge reduction for the entire country, followed by that of Shandong and Zhejiang provinces. In contrast, such reductions in Hainan, Qinghai and Gansu will result in the least amount of industrial wastewater discharge reduction for the entire country under the same conditions.

(3) The sensitivity of Chinese industrial wastewater discharge reduction is determined by the existing Chinese provincial industrial structure, industrial developmental policy and environmental policy. Only by taking industrial associations and regional ties into consideration can we properly achieve the maximum industrial wastewater discharge reduction across the entire country. In the '12th Five-Year Plan', paying close attention to the improvement in production technological levels and organizational efficiency, such as increasing the service sector's share of input, can help lessen these direct input 
coefficients and effectively achieve a reduction of industrial wastewater discharge through industrial restructuring on a path of remaking industry.

\section{References}

Chen Xikang, Li Bingquan, Yan Shuhai et al., 1985. Economic Mathematics Method and Model (Revised Edition). Beijing: Chinese Finance and Economics Publisher. (in Chinese)

Chen Xikang, Yang Cuihong et al., 2011. Input-Output Technique. Beijing: Science Press. (in Chinese)

Fan Wei, 2008. A decomposable analysis of influential factors on environmental pollution in China based on SDA technique and PDM method: Exampled by air pollution. Thesis for Master's degree. Shenyang: School of Business Administration Northeastern University. (in Chinese)

Guan D B, Hubacek K, 2007. Assessment of regional trade and virtual water flows in China. Ecological Economics, 61(1): 159-170. doi: 10.1016/j.ecolecon.2006.02.022

Jiang J Q, Lloyd B, 2002. Progress in the development and use of ferrate (VI) salt as an oxidant and coagulant for water and wastewater treatment. Water Research, 36(6): 1397-1408. doi: 10.1016/j.bbr.2011.03.031

Jiang Yan, Wen Jianping, Hu Zongding, 2004. Development of new technology and method in industrial wastewater treatment process. Chemical Industry and Engineering Progress, 23(3): 256-259. (in Chinese)

Johnson M H, Bennett J T, 1981. Regional environmental and economic impact evaluation: An input-output approach. Regional Science and Urban Economics, 11(2): 215-230. doi: 10.1016/0166-0462(81)90005-3

Kneese, A V, Ayres R U, D'Arge R C, 1970. Economics and the Environment: A materials Balance Approach. London: the Johns Hopkins Press.

Leontief W, 1970. Environmental repercussions and the economic structure: An input-output approach. The Review of Economics and Statistics, 52(3): 262-271. doi: 10.2307/1926294

Leontief W, 1986. Input-Output Economics (Second Edition). New York: Oxford University Press.

Li L L, Qi P, 2011. The impact of China's investment increase in fixed assets on ecological environment: An empirical analysis. Energy Procedia, 5: 501-507. doi: 10.1016/j.egypro.2011. 03.087

Li Lei, Pan Huiling, 2011. Prediction of industrial wastewater discharge amount based on multivariate nonlinear regression. Journal of Jiangnan University (Natural Science Edition), 10(3): 309-313. (in Chinese)

Li Mingsheng, Tong Lianjun, Qiu Fangdao, 2009. Factor decomposition and reduction effect on the changes of industrial wastewater discharge. Environmental Science, 30(3): 707-712. (in Chinese)

Liu Ping, Wang Chao, Wei Yuansong et al., 2011. Effects of technology progress and industrial structure on the industrial wastewater discharge of Tianjin. Acta Scientiae Circumstan- tiae, 31(5): 1098-1104. (in Chinese)

Liu Weidong, Chen Jie, Tang Zhipeng et al., 2012. China's 30 Provinces' Multi-regional Input-Output Table Theory and Practice in 2007. Beijing: China statistics press. (in Chinese)

Lu Houlu, Liu Deqi, 2006. Summary of industrial wastewater treatment technologies. Environmental Protection in Petrochemical Industry, 29(4): 15-19. (in Chinese)

Ma X Y, Ortolano L, 2000. Environmental Regulation in China: Institutions, Enforcement, and Compliance. Lanham, Maryland: Rownman \& Littlefield Publishers.

Managi S, Kaneko S, 2009. Environmental performance and returns to pollution abatement in China. Ecological Economics, 68: 1643-1651. doi: 10.1016/j.ecolecon.2008.04.005

Miller R E, Blair P D, 1985. Input-Output Analysis: Foundations and Extensions. New Jersey: Prentice -Hall, Englewood Cliffs.

Ministry of Environmental Protection of the People's Republic of China, 2003. National Environmental Statistical Bulletin 2002. Available at: http://zls.mep.gov.cn/hjtj/qghjtjgb/200306/ t20030605_85524.htm. (in Chinese)

Ministry of Environmental Protection of the People's Republic of China, 2008. National Environmental Statistical Bulletin 2007. Available at: http://zls.mep.gov.cn/hjtj/qghjtjgb/200809/ t20080924_129355.htm. (in Chinese)

National Bureau of Statistics of China, 1992-2008. Statistical Yearbook of China, 1991-2007. Beijing: China Statistics Press.

National Bureau of Statistics of China, 2009. Input-Output Tables of China in 2007. Beijing: China Statistics Press. (in Chinese)

Okadera T, Watanabe M, Xu K Q, 2006. Analysis of water demand and water pollutant discharge using a regional inputoutput table: An application to the city of Chongqing, upstream of the Three Gorges Dam in China. Ecological Economics, 58(2): 221-237. doi: 10.1016/j.ecolecon.2005.07.005

Rhee J J, Miranowski J A, 1984. Determination of income, production, and employment under pollution control: An inputoutput approach. The Review of Economics and Statistics, 66(1): 146-150. doi: 10.2307/1924707

Schnabl H, 2003. The ECA-method for identifying sensitive reactions within an IO context. Economic System Research, 15(4): 495-504. doi: 10.1080/0953531032000152344

Shen Chenwen, Qi Guoyan, Zhou Huimin, 2010. An analysis of industrial wastewater hazards caused by organic pollutant. China Practical Medicine, 5(28): 264-265. (In Chinese)

Sherman J, Morrison W J, 1950. Adjustment of an inverse matrix corresponding to a change in one element of a given matrix. Annals of Mathematical Statistics, 21(1): 124-127. doi: 10.1214/aoms/1177729893

Shi Minjun, Zhang Zhuoying et al., 2012. Chinese Provincial Input-Output Model and Regional Economic Linkage. Beijing: Science Press. (in Chinese)

Sonis M, Hewings GJD, 1992. Coefficient change in input-output models: Theory and applications. Economic Systems Research, 14(2): 143-157. doi: 10.1080/09535319200000013

Sonis M, Hewings G J D, Guo Jiemin, 2000. A new image of classical key sector analysis: Minimum information decomposition of Leontief inverse. Economic Systems Research, 12(3): 
401-423. doi: 10.1080/09535310050120952

Tang Zhipeng, Fu Xue, Wei Xiaojun, 2009. Research on identifying important coefficients in Chinese sectors with high industrial wastewater discharge. Asia-Pacific Journal of Management Research and Innovation, 5(2): 39-48. doi: 10.1177/ 097324700900500203

Tang Zhipeng, Fu Xue, Zhou Zhien, 2008. Identifying important coefficients in China's sectors of discharge amount of industrial wastewater. China Population, Resources and Environment, (5): 123-127. (in Chinese)

Tang Zhipeng, Liu Weidong, Liu Zhigao et al., 2011. Regional difference and convergence of standardized discharge of industrial wastewater in China. Geographical Research, 30(6): 1101-1109. (in Chinese)

Tang Zhipeng, Wang Peihong, 2007. Identifying important coefficients in input-output model by losing information method. Journal of Mathematics in Practice and Theory, 37 (14): 220-226. (in Chinese)

Tarancón M A, Río P D, Albiñana F C, 2010. Assessing the influence of manufacturing sectors on electricity demand: A cross-country input-output approach. Energy Policy, 38(4): 1900-1908. doi: 10.1016/j.enpol.2009.11.070

Tarancón M A, Río P D, 2012. Assessing energy-related $\mathrm{CO}_{2}$ emissions with sensitivity analysis and input-output techniques. Energy, 37(1): 161-170. doi: 10.1016/j.energy.2011.07.026

Wen Jiabao, 2011. Report on the Work of the Government: Delivered at the Fourth Session of the Eleventh National People's Congress. Beijing: State Council of the People's Republic of China. (in Chinese)

Xie Hongbin, Liu Zhaode, Chen Wen, 2004a. Quantitative analysis on the influential factors of industrial waste drainage. Resources and Environment in the Yangtze Basin, 13(4): 394398. (in Chinese)
Xie Hongbin, Ye Geyang, Xie Yongqin, 2004b. Quantitative analysis of the effects of industrial structure change on the industrial waste drainage. Journal of Fujian Normal University (Natural Science Edition), 20(4): 90-93. (in Chinese)

$\mathrm{Xu}$ Jian, 2003. Determination of the important coefficient in inputoutput model. Statistical Research, (9): 53-56. (in Chinese)

Xu S, Madden M, 1991. The concept of important coefficients in input-output models. In: Dewhurst JJ et al. (eds.). Flexibility and Extensions in Regional Input-Output Modelling. Aldershot: Avebury, 66-77.

Yu Fang, Cao Dong, Wang Jinnan et al., 2009. Prediction of industrial wastewater discharge and abatement expenditure. Research of Environmental Sciences, 22(8): 971-976. (in Chinese)

Yu Fang, Zhang Qiang, Guo Xiaomin, 2003. Pollution characteristics of main industrial wastewater sub-sectors in China and control focuses. Environmental Protection, (10): 38-43. (in Chinese)

Zhang J, Deng S H, Zhang Y Z et al., 2011. A new model concerning the relationship between industrial wastewater generation, abatement rate, discharge and economy in China. Procedia Environmental Sciences, 11(B): 803-809. doi: 10.1016/ j.proenv.2011.12.123

Zhang Shuqin, 2011. Assessment and discharge of industrial wastewater of Fushun city. Northern Environment, 23(9): 120-165. (in Chinese)

Zhong Qifu, Chen Xikang, Liu Qiyun, 1993. Input-Output Analysis (2nd Edition). Beijing: China Financial and Economic Publishing House. (in Chinese)

Zhou Lijun, 2010. Relationship between the discharge of industrial wastewater and the investment in environmental governance of Jiangsu. Environmental Science and Management, 35(12): 30-32. (in Chinese) 